\section{Investigating the healing arts of Ancient Mesopotamia}

\begin{tabular}{l|l} 
Barbara Boeck, of the Institute & arly in Ancient Mesopotamia's \\
for Mediterranean and Near & history (mid-fourth millennium BC), \\
Eastern Languages and & cuneiform records using impressed \\
Cultures, CSIC Madrid, has & signs on wet clay were invented. Among \\
studied the cuneiform records & these records were many medical \\
of Ancient Mesopotamia to & prescriptions and a few pharmacological \\
explore their healing methods. & manuals. Over time, the arrangement \\
With a particular focus on & of these texts varied but, aside from \\
medicinal plants and the & subtle changes in drug terminology, little \\
practice of divination, she set & changed in Babylonian pharmacology \\
out to discover how Babylonian & or approach to medicine. Deciphering \\
practitioners treated their & these texts is complex but provides \\
patients, what medicinal & fascinating insights into the Babylonian \\
plants they recommended for & concept of healing and their knowledge \\
which illnesses, and how they & of medicinal plants. \\
explained pain and illness. & \\
Barbara describes how the & Around 5000 medical prescriptions \\
Babylonian concept of healing & have been found in libraries of King \\
included religious belief and & Assurbanipal of seventh-century \\
magic. She collaborates with & Nineveh, and in temple and private \\
Amots Dafni in studying & libraries and hoards from other \\
medicinal plants and lgnacio & Neo-Assyrian cities and cities of \\
Márquez Rowe regarding the & sixth- to third-century Babylonia. First \\
divinatory technique of extispicy. & pharmacological texts date to the \\
& second half of the third millennium BC, \\
& being unearthed at the ancient city of \\
& Ebla (located in the ldlib Governarate, \\
& Syrial. However, the majority comes \\
again mostly from Assurbanipal's
\end{tabular}

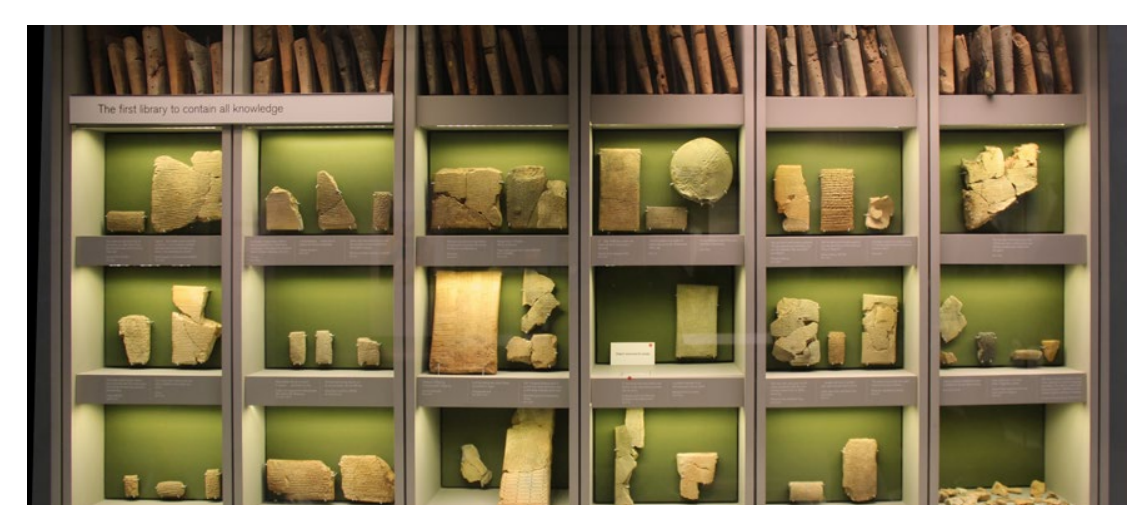

library. They record nomenclature and lexicographical issues, descriptions of plants, and herbals that link plants with
the ailments they alleviate.

This cuneiform literature provides were competent in curing diseases or complaints, often using multiple prescriptions for the same problem. Barbara Boeck and colleagues continue to mine these records for insights into the healing methods of those times, as described here.

\section{MEDICINAL PLANTS OF}

ANCIENT MESOPOTAMIA

One of the best-documented cuneiform medical sources is a lexicon of drug terms, the Uruanna: maštakal (meaning the plant whose home is heaven is 1300 terms for drugs of pant about which, taking drugs of plant origin and synonyms, describe ariants different plants. Plants (herbs, trees and bushes, spices, grasses, algae, aromatic plants and fungi) dominated Babylonian healer's repertoires; many

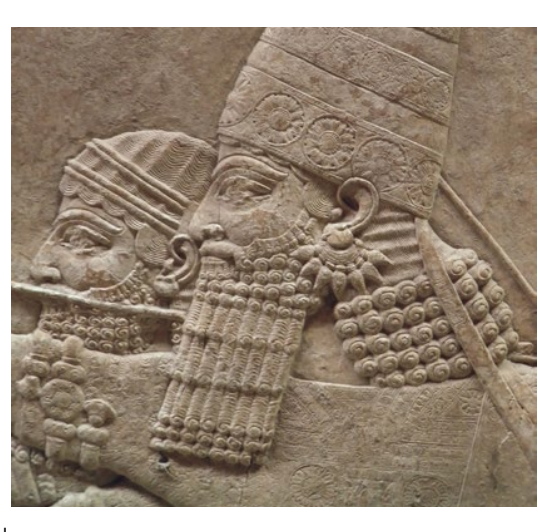

were also common foods (onion, garlic, pomegranate, fig and date).

Written records helped practitioners to recognise and collect medicinal plants main source for plant descriptions was the manual Šammu Šikinšu (meaning 'the appearance of the medicinal drug') which cannot be fully reconstructed from surviving tablets. While medical recipes often involved entire plants rather than parts, plant descriptive texts provided more on the parts and their efficacy (roots, stems, leaves, flowers, fruits and seeds) and on plant products (flour, powder, chips and ashes).

So far, few medicinal plants have been identified with certainty, and correlation between plant names and samples or are used for different plants and the ancient approach to plant classification is inadequate for modern botany. From written records, it is difficult to determine what substances of animal origin or minerals (often described only as 'stone') were used medicinally. Some terms are clearly animals but, when mentioned as 'of the field' in medical recipes, they are actually plant names. Although there is archaeobotanical information for many ancient sites, not every region and period is covered.

Information on sources of medicinal plants comes from letters, while likely places for cultivating them are given in reports about the deeds of the Assyin
kings that include their botanical gardens. One such text records 28 trees, known from other sources to be of medicinal value. This may be significant since pharmacological and medical texts refer to only 35 trees or shrubs used as medicines. A small tablet ascribed to king Marduk-apla-iddina, who ruled Babylon in the eighth century BC describes 67 plants in his garden, half of which were medicinal.

There are references to plant habitat in plant description texts and medical recipes, as well as advice on correct times and methods of harvest. Documents like the drug inventory from Assur, dating from the seventh century

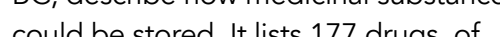
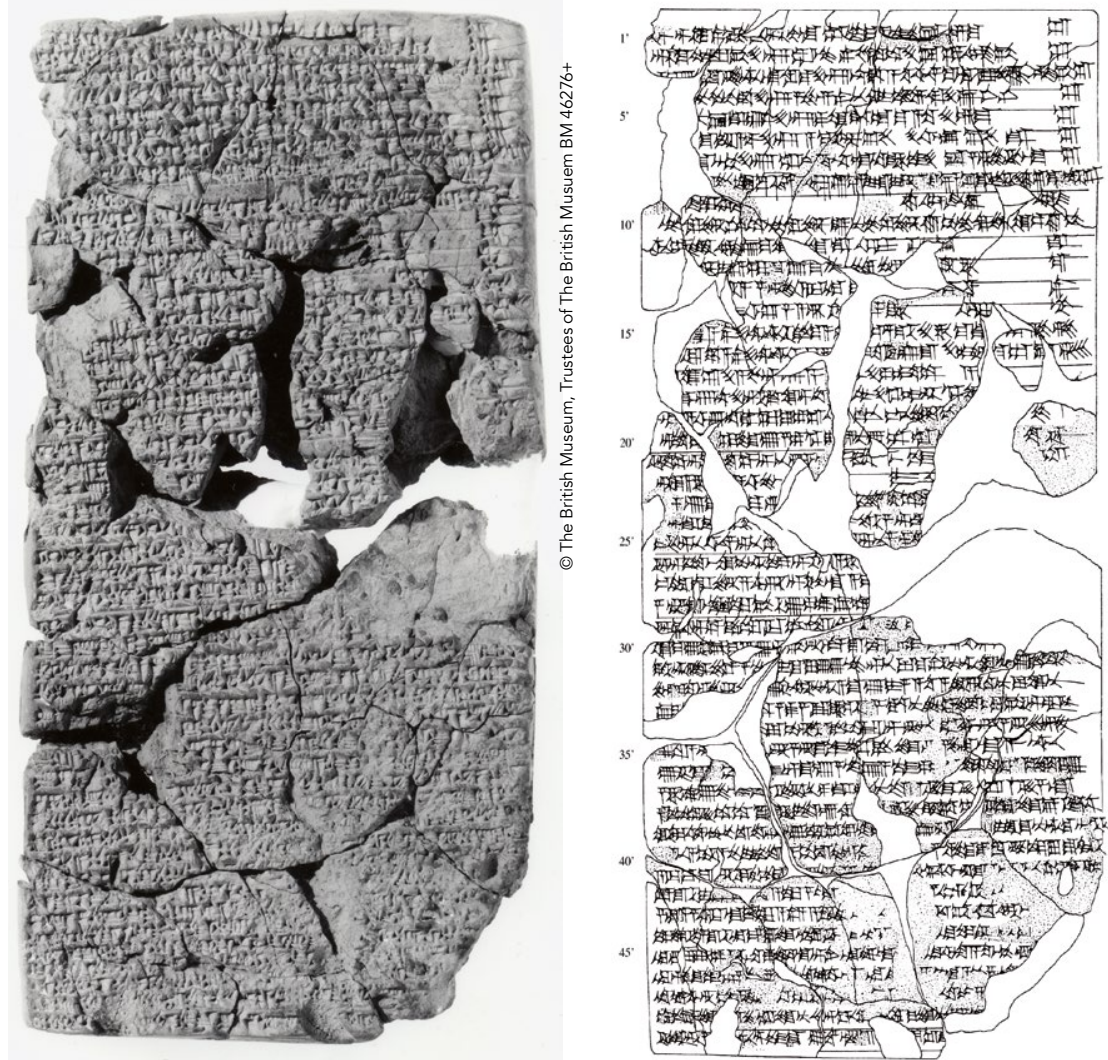
Right: A hand-copy of the obverse of a cuneiform tablet that contains incantations that were recited
during the therapy of massaging a patient. Cuneifirm signns consist of usually several wedges, so
missing one wedge can lead to a wrong reading of the sign and consequenty to a wrong translation of

Cuneiform literature provides evidence that ancient practitioners were competent in curing ailments, often using multiple prescriptions for the same problem.

which 159 (about half the known number of drugs from Mesopt
are of plant origin.

Boeck and Dafni have collaborated in the task of accurate identification of use and administration. They revisited the healing plants mentioned in the Bible. Working together with specialist botanists, they were able to revise the number of Biblical medicinal plants, autreach article.

HEALING THROUGH

\section{MEDICINE OR MAGIC}

For Babyonians, healing addressed wellbeing in religious, social and

psychological terms, while curing meant treatment and removal of illness. They substances that they knew influenced certain functions of the body. In med demon was treated in the same way indicating that choice of treatment did not depend on religious, magical or natural perceptions of disease. However practitioners responded to the double nature of disease-illness or demon-by using different incantations.

Religious premises lay behind the choice of medicinal plants to treat specific Medical incantations, recited to and medication, were recorded; Boeck has reconstructed over 60 such incantations. Pains were thought to be caused by a specific disease-demon th was given different names according guarantee the efficacy of both treatmen 


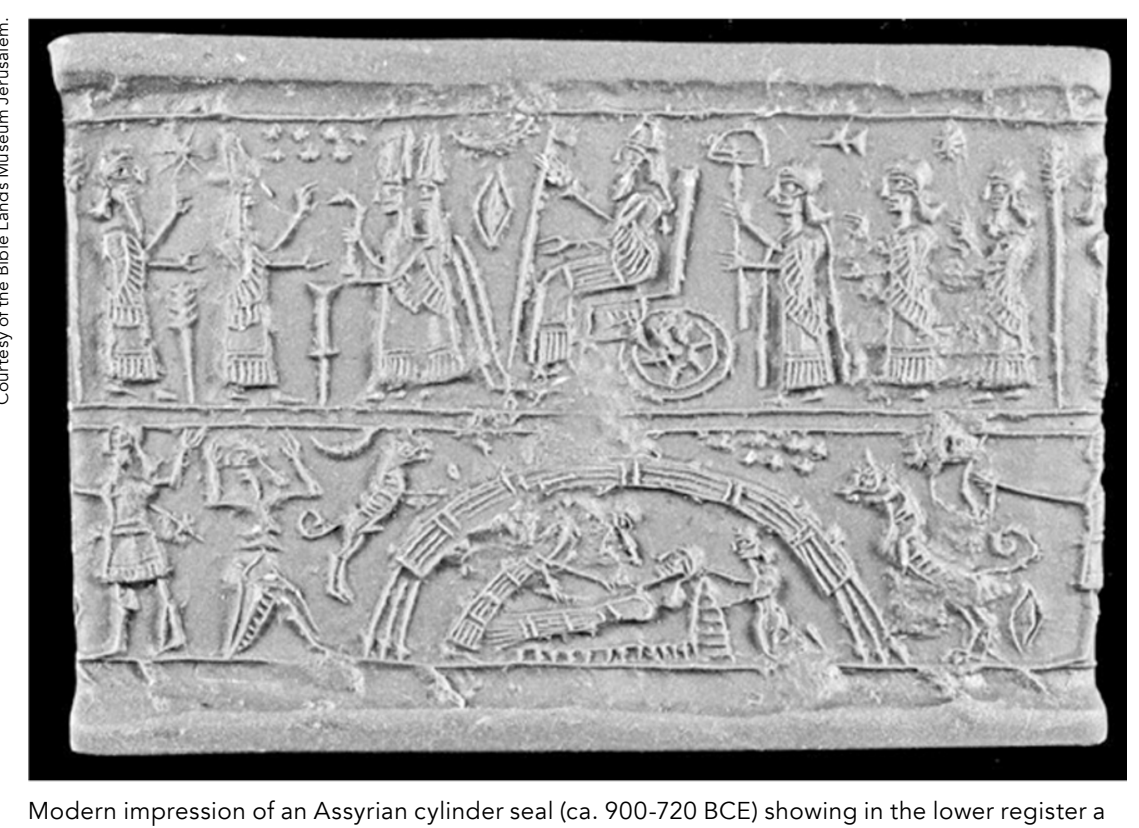

healing scene in a reed ant. Two dogs, the animal of the ancient Mesopotamian healing goddess
Gula, flank the hut in order to protect the patient.

Written records helped practitioners to recognise and collect medicinal plants and to avoid poisonous plants.

treatment aimed to drive the demon from the body.

Disease was not explained as dysfunction of the body or as deviation from its normal state but rather in metaphysical terms, establishing analogies and correspondences between plants and diseases or disease and deities or other supernatural powers. Some of the metaphysicial analogies were connected wh the

While completing the lifetime project of her teacher Franz Koecher (who was preparing the text edition of Uruanna, Šammu šikinšu, lists of simple drugs and medical prescriptions at the time of his death in 2002), Boeck came across a line that associated a plant named 'Ninigizibara's dog' with Gula. This led her to study afflictions attributed to Gula and cured with Gula's plants. She hoped it would help her discover whether the medical literature reflected understanding of the healing goddess she is described in religious texts.

Boeck divided the body of medical writing into three parts: diagnostic

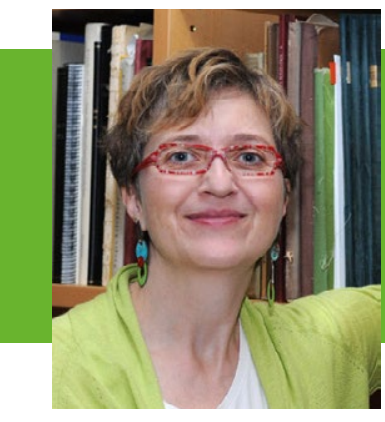

\section{Behind the Research}

Dr Barbara Boeck

E: barbara.boeck@cchs.csic.es T: +34916022315 W: http://ilc.csic.es/es/research-group/ letras-ciencias-antigua-mesopotamia-lycam

names for the same plant could reflect ( some uses. The strong connection fGla with dogs appeared to be an allusion to protection, both literal and medical.

Boeck suggests that Gula's plants did have medicinal properties but that the religious concept of the healing goddess enhance their efficacy. An example is the ideas about biliary diseases and digestive disorders. Gula governed the bile, which was thought to regulate the body fluids of the intestines. To aid healing, incantations to her were recited. Meanwhile, treatment consisted in the prescription of medicinal plants, which were in fact emetics goddess,

\section{DIVINATORY TECHNIQUES}

It was believed that calamities foreseen two such practices: (1) prediction of a person's character and fate by reading facial expressions, body shape and way of talking (physiognomy); and (2) reading of entrails of sheep (extispicy or haruspicy). Until 20 years ago, little was known about the first method, probably used to choose a good wife or trusted servant. Boeck recovered and pieced together a physiognomic treatise, identifying and deciphering fragments for over 100 years unread).

The second divinatory technique (extispicy) is the subject of Boeck's most recent research. Babylonians were famous for examining the liver (Old Testament, Ezekiel 21:26) but little is intestine of sheep. Over the last 15 years, Boeck and Ignacio Márquez Rowe have gathered testimonies for these practices, including divination texts and depictions of the colon drawn to teach apprentice diviners. To make predictions for their clients (notably kings), diviners observed how the sheep's colon coiled. For example, coils covered with hard people to forestall them. Boeck studied known about their study of the large

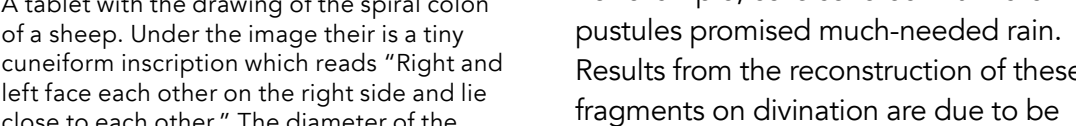

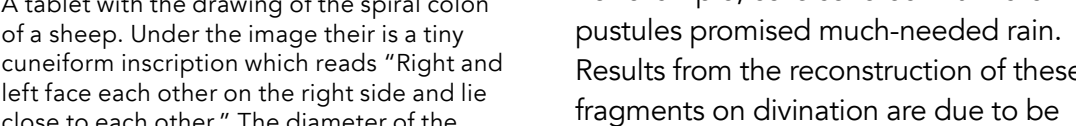
left face each other on the right side and lie
clsese to each other." The diameter of the
almost round tablet is $11.2 \mathrm{~cm}$.

\section{Research Objectives}

Barbara Boeck is interested in ancient Mesopotamian healng terkis is with special focus on medicinal plants

\section{Detail}

Bio

Dr Barbara Boeck is Senior Researcher at the Institute for Mediterraneen and Near Eastern Languages and Cultures, CSIC Madrid. Interested in ancient Mesopotamian healing therapies with special focus on medicinal plants and the practice of divination, in particular physiognomy and haruspicy. Her books include the edition of ancient Mesopotamian physiognomic divination (2000), a treatise on Sumerian and Akkadian healing incantations (2007), and a study on Babylonian medicine (2014).

\section{Funding}

Research was funded principally by the Spanish Ministry of Science or granted by the Spanish National Research Council (CSIC) in a number of research projects

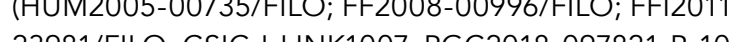
23981/FILO; CSIC-HINK1007; PGC2018-097821-B-100).

\section{Collaborators}

Dafni (Institute of Evolution, Dept. of Haifa, Israll) is collaborting in the study of medicina plants in the ancient world.

- Dr Ignacio Márquez Rowe (Institute for Mediterranean and Near Eastern Cultures and Languages, CSIC, divinatory technique of extispicy.

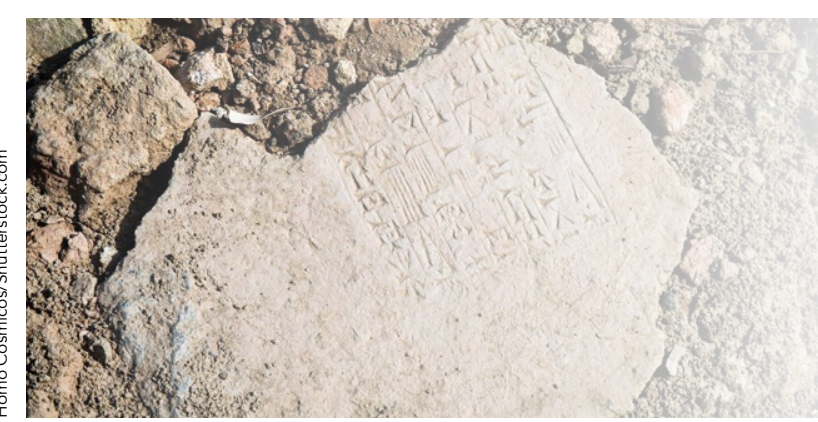

\section{References}

Böck, B. (2011) Sourcing, organizing, and administering medicinal ingredients, Ch. 32. The Oxford Handbook of Cuneiform Culture (eds K. Radner \& E. Robson) Oxford University Press.

Böck, B. (2015) Shaping Texts and Text Genres: On . Editorial AUSA.

Böck, B. (2014) The Healing Goddess Gula: Towards an Understanding of Ancient Babylonian Medicine (Culture and History of the Ancient Near East). Brill.

Dafni, A. \& Boeck, B. (2020) Revisiting the medicinal plants of the Bible and the Holy Land. Research Outreach 114 medicinal-plants-bible-holy-land/

\section{Personal Response}

Would you like to say something about the possible 列 medicine or history of medicine or plant biology? II The immediate use for modern medicine depend heavily on the question whether the cuneiform plant names can be identified with botanical species. I am rather sceptical about finding new medicinal plants but I believe that it is perfectly possible to discover not yet

The cuneiform evidence testifies to the broad experience of Assyrian and Babylonian healers
with plants. Actually, many of the uses tally with the information of the ancient Greek plant lore, pointing to a cleart The history of medicine commonlye East to the beginnings of the Western tradition to ancient Greeks

\section{CSIC}

